\title{
Competition For Versus In the Market of Long-Distance Passenger Rail Services
}

\author{
Frédéric Cherbonnier \\ Marc Ivaldi \\ Catherine Muller-Vibes \\ Karine Van Der Straeten
}

April 15, 2018

\begin{abstract}
This paper is aimed at evaluating the net gains and trade-offs at stake in implementing the competition of the rail mode in the long distance passenger market either by means of franchise or by an open access mechanism. We simulate the outcomes of competition in and for the market using a differentiated-products oligopoly model allowing for inter- and intra-modal competition in a long distance passenger market. Specifically we first calibrate the model using data describing high speed lines in France and show that the incumbent railway operator's strategy does not simply boil down to a short-term profit maximization (e.g., because of existing regulation or limitpricing strategy). This yields two important results when simulating competition. First, whether it is for or in the market, the opening to competition does not guarantee a decrease in prices in favor of passengers. Second, the effects of opening up to competition for the market are relatively predictable and potentially positive, while those of opening up to competition in the market remain very uncertain.
\end{abstract}

JEL Codes: L13, L90, R40

Keywords: Intermodal competition, Oligopoly model, Open access.

Acknowledgment

The authors would like to thank Julien Brunel, Grégoire Marlot, Emile Quinet, Jean Tirole for helpful comments. The opinions expressed in this paper reflect only the authors' views.

\footnotetext{
Authors

Frédéric Cherbonnier, Toulouse School of Economics and Sciences-Po Toulouse, frederic.cherbonnier@gmail.com;

Marc Ivaldi; Toulouse School of Economics, CEPR and CESifo, marc.ivaldi@tse-fr.eu, corresponding author; Catherine Muller-Vibes, Toulouse Business School, catherine.muller@tbs-education.fr;

Karine Van Der Straeten, Toulouse School of Economics, CNRS, and Institute for Advanced Study in Toulouse, email: karine.van-der-straeten@tse-fr.eu.
} 


\section{Introduction}

With the 4th railway package, the European Union has set a legal framework that provides for an opening to competition of high speed passenger services from 2020 onwards. The stated objective is to induce a downward pressure on costs as well as a strengthening of the offer of services for the benefit of the passenger. To do so, this framework advocates as base method, an open access policy, also called competition in the market, that is to say, an opening of the market to allow several operators to run trains on the same line, and leaves it to each Member States to precise the modalities on its own network.

However, access to a railway infrastructure requires a prior allocation of train paths, which could require the regulator to auction, for an entire market (for instance, an origin-destination link), a certain number of train slots, without determining in advance the number of operators that would ultimately be providing the transport services. When only one operator is selected, this framework is classified under the category of competition for the market where competitive pressure occurs ex ante, i.e., each time the auction process is renewed. It is similar to the allocation of rail franchises.

This paper is aimed at evaluating the net gains and trade-offs at stake in implementing the competition of the rail mode in the long distance passenger market either by means of franchise or by an open access mechanism.

\section{European experiences}

This question is all the more important as the experiences of open access in Europe do not seem successful so far. While a regulation in 2014 allowed open access to rail in fifteen European countries, it has been effective in only six countries, and this in a very limited way outside the Italian case.

An open access scheme was introduced in Germany in 1994 in the freight and longdistance passenger transport. Access to the network is based on the free demand of the competitors of DeutscheBahn, without any particular regulation being provided for the pricing of access. (See Link, 2004.) Between 2000 and 2010, there were 10 attempts to enter the long-distance market, all of them with a very limited volume (no more than 2 round trips per day). Six of them closed after a relatively short period. (See Séguret, 2010.) At the end of this period, the total market share of the operators who accessed the network in open access remained below $1 \%$.

In the case of the United Kingdom, the bulk of passenger transport is provided by companies that have obtained regional franchises through a tendering procedure. Today, there are 16 regional franchises on the British market. The Office of Rail and Road (i.e., the rail regulator) can however grant an open access to operators on certain routes via a codified procedure. The first operator in open access was the company Hull trains which obtained in 2000 the rights for a period of 10 years (extended since then to 2016) to operate between London and Hull a service comprising 7 trains per day in 2011. The company Grand Central was then granted train slots connecting London to Sunderland in 2007 and then Bradford in 2009. A third operator, Wrexham and Shropshire, got train slots to Wrexham but withdrew three years later due to the lack of profitability of these routes. In total, open access traffic now accounts for less than $1 \%$ of traffic measured in passenger kilometers in the United Kingdom. (See Competition \& Market Authority, 2015 and 2016.)

In these two examples, the market share of operators entering in open access is very low, both at national level (less than 1\% for all these operators) and at each route (less than $5 \%$ in the United Kingdom, between 5 and 10\% in Germany). 
Examples exist, however, where such operators have obtained a more significant market share on a few markets, in particular in Czech Republic where two operators have a combined market share of between $40 \%$ and 50\% on the Prague-Ostrava route since 2012 and in Austria where the operator Winbah's market share is around $25 \%$ on the Vienna-Salzburg route. In both countries, access to the rail network is not restricted a priori, but market competition has only been effective on a single link. Sweden is not an exception: Three operators are present on the three main long-distance links in the Stockholm-Gothenburg-Malmö triangle and are providing highly differentiated services, in particular cheaper and slower trains than the incumbent operator, for a total market share of less than $2 \%$. Note, however, that, in 2015, a new operator entered in direct competition with the incumbent on the Stockholm-Gothenburg route.

Italy is in fact the only case where the market share of the operator that entered in open access is significant. The operator NTV, entered on the market in 2012, thus reached in 2013 a market share in the order of $22 \%$ on two high-speed lines, Turin-Milan-Venice and Milan-RomeNaples. This entry was not made without difficulty. The new entrant seems to have suffered the lack of possibility to buy rolling stock; the incumbent owning the existing rolling stock, NTV had to make heavy investments. The regulator sought to correct this discriminatory situation as early as 2013 by uniformly reducing the infrastructure access charges.

In the light of these examples, the outcome of open access in the railway industry is therefore mixed. However, when a competition in the market is put in place significantly, it seems to induce positive effects for the passenger. According to Bergantino, Capozza and Capurso (2015) and Bergantino and Capurso (2015), the open access in the Italian market would have led to an overall increase in rail supply and a significant transport price decrease (i.e., including the fares of air tickets) without leading the incumbent operator to engage in a too aggressive price war.

These facts call for an examination of the viability of the open access policy as the method to open the rail markets to competition.

Now, competition for the market does not always generate the expected efficiency gains either. For the United Kingdom, several studies tend to show that the opening to competition for the market has not significantly improved the efficiency of operators. According to Smith, Nash and Wheat (2009) and to Smith and Wheat (2012), the cost of franchised operators increased between 1997 and 2006, a finding that led the British regulator to consider different avenues to increase competition in this sector, mixing competition for and in the market. ${ }^{1}$ (See the Report of the Office of Rail and Road, 2015.)

\section{Literature}

The economic research has identified different causes that could explain the outcomes of the opening to the rail market from various angles. First, they are related to factors pertaining to demand such as the Mohring effect. Losing market shares implies for the incumbent a decrease in the frequency of its trains on the link in competition, which reduces its attractiveness on this market for the consumers and also threatens its profits on other adjacent adjacent services because of complementarities of demand on contiguous sections of the rail network. Hence, the pattern of demand may explain why the incumbent is proving to be a more aggressive competitor than its operating costs would suggest. (See Seabright, 2003.)

Second, the rail industry is characterized by significant economies of scale, more precisely by economies of density and scope. The immediate consequence is that we can not expect many competitors in a rail market. These economies of scale depend on the characteristics of the

1 For a review of the state of rail competition in Europe, see also Nash (2018). 
operator in terms of size or type of network, notably with economies of scope being increasing or decreasing depending on the case, and economies of density being increasing depending on the mode of opening to competition. (See Smith and Wheat, 2015.) Recent work by Rasmussen, Smith and Wheat (2015) finds a cost-elasticity to density of 0.32 for a new entrant and of the order of 1 for the franchised operator. In these conditions, differences of cost efficiencies among operators can play a crucial role in the process of opening to competition.

The economic literature has also documented the effects of the opening to competition. For the United Kingdom, the role of demand and the choice of transport modes has been emphasized in articles based on the PRAISE model. (See Preston, Wardman and Whelan, 1999, Preston, Holvad and Raje, 2002, and Johnson and Nash, 2012.) These articles predict the impact of fares and services on the volume of rail traffic per operator, based on multiple scenarios, but do not model the strategic behavior of operators. For Spain, Álvarez, Cantos, Moner and Sempere (2015) consider the two lines connecting Madrid to Seville and to Valencia. They use traffic and price data to calibrate their model of demand and general data available in the literature on the operational costs of rail and air transport as well as infrastructure access charges communicated by the operators themselves to calibrate their supply model. (See Campos and De Rus, 2009 and Swan ad Adler, 2006.) Their analysis shows that open access would have a positive effect in terms of social welfare only if it generates a price reduction sufficient to lead to an increase in traffic of about $25 \%$. Their assumption on the costs of the new entrant, which are $25 \%$ lower than those of the incumbent operator, does not allow to reach this volume of traffic, which leads the authors to provide a negative judgment on the opening in open access. Note that these conclusions are based on the idea that the incumbent maximizes social welfare today, not profit. This approach leads them to assume that the new entrant practices higher prices, and thus induces both a diversification of supply and a rise in prices.

For Germany, Ivaldi and Vibes (2008) propose a simulation model to analyze inter and intra-modal competition on the Cologne-Berlin route, simulating the entry of a low cost rail operator which provides the same service as the incumbent, but has marginal costs half as high. In this specific market, there is inter- and intra- modal competition. This article shows that the entry of a low-cost rail operator is possible, it would lead to a price reduction of $30 \%$ and it would capture more than $25 \%$ of market share to the detriment of the incumbent and air carriers, with a strong positive impact on social welfare. The assumption on the costs of the low-cost operator is however strong compared to the observations, i.e., a division by two of marginal costs compared to those of the existing railway service. The main lesson of this article is that the equilibrium on the market depends to a large extent on the strength of competition from other modes of transport.

\section{Methodology}

Building on this literature, we propose here to assess the costs and benefits of opening the rail market to competition by simulating the outcomes of competition in and for the market using a differentiated-products oligopoly model allowing for inter- and intra-modal competition in a long distance passenger market. It is a benchmark model extensively applied to quantitatively assess the degree of competition in a given market or to measure consumer harms in anticompetitive cases. In this setup, the transport services supplied by the operators are differentiated in terms of quality, which notably depends on typical transport characteristics like the frequency of the service; on a given market (i.e., a city-pair) consumers (i.e., potential passengers) choose a transport service (namely, a transport mode) as well as an operator; and operators strategically decide on prices for the service they provide. This tool allows us to derive the market equilibrium conditions (i.e., market shares, prices and profits of operators, consumer surplus of consumers) 
and to simulate various scenarios depending on the mechanism chosen to open the rail sector to competition. It is designed to be calibrated and used with a limited amount of detailed data.

Specifically, we consider the link between Paris and Marseille whose distance by road is around 750 kilometers, which allows for intermodal competition between road, rail and air transport modes. We consider the leisure segment on which four competitors operate: the national rail operator, an airline, the private car operator (a driver operating his/her own car) and a car sharing operator. We also look at the business segment of the Paris-Bordeaux market where only the rail and air competitors are present. In both cases, passengers may finally decide not to travel.

\section{Results}

Two main lessons can be drawn from our simulations. First, whether it is for or in the market, the opening to competition does not guarantee a decrease in prices in favor of passengers. On the contrary, they could increase significantly if some form of tariff distortion experienced by the historical monopoly today were to be relaxed. The calibration of the model tends to show that the actual prices of the incumbent are significantly below what would be optimal for a company in a monopoly position on the rail mode that would maximize its short-term profit without constraint. This low level of margins could equally well be interpreted in terms of supply, which would emerge at a higher level because of a voluntarist policy. Further work remains to be done to better understand what determines today these distortions favorable to users. These may result from the current price regulation, the rail operator's strategy to anticipate a possible tightening of this regulation or the entry of a competitor, or as the result of political pressure likely to lead to the deployment of a too expensive network and offer of service. At the extreme, the simulations carried out indicate that, if the opening to competition leads to the total elimination of all tariff distortions, the price increase could reach $24 \%$ depending on the scenario considered.

Second, the effects of opening up to competition for the market are relatively predictable and potentially positive - while those of opening up to competition in the market remain very uncertain. In the former case, it should be possible in principle to maintain the general tariff distortion towards lower prices mentioned in the previous paragraph, and the supposedly best efficiency of the franchise operator would then automatically translate into a gain for the passenger. Indeed, a 10\% reduction of operating expenses leads to a $3 \%$ decrease in prices. In the latter case, the downward pressure on prices would naturally relax, and competition from the new entrant would not always counteract this effect. This will strongly depend on the number of train slots granted to the new entrant: An insufficient number of slots would lead to conceding a derisory market share of a few percent and prevent a priori any entry as was observed in Germany, while a balanced sharing as in Italy would, in France, allow an effective entry with a potentially positive but very uncertain effect for the passenger.

This rather leads to advocate the passage of calls for tenders on a line (or a set of lines) cut into a few packets of slots, likely to entrust the operation to two or even a single company depending on the result of the call for tenders. In this latter case, there would be competition for the market with only one franchise operator, whereas the former case would be similar to in the market competition with the public authorities predefining the terms of the line sharing. This approach would have the advantage of a more complete questioning of the organization of the network and would thus be more likely to lead to efficiency gains. ${ }^{2}$

2 In a recent report, Nash, Crozet, Nilsson and Link (2016) reach a similar conclusion as they wrote: "In the case of ontrack competition, which mainly affects high-speed rail, it will be very difficult to establish head-on competition between SNCF and a new entrant on the most profitable lines, given that capacity is limited. [...] Just as in PSO services, as suggested by C. Nash (2009) or J. Preston (2009), competition in the high-speed segment in France can probably only 


\section{Map of the analysis}

We implement this analysis in the following way. In Section 2, we present the data needed to calibrate the model. Section 3 introduces the model of intra- and inter- modal competition between transport alternatives. The calibration is discussed in Section 4 while Section 5 examines the results of the simulation of the competition for and in the market. Section 6 concludes.

\section{Data}

To develop our model of intermodal competition and a methodology to analyze it, we consider two important markets in France, namely Paris-Marseille and Paris-Bordeaux, both connected with a high speed infrastructure. Both these origin-and-destination pairs connect Paris to two of the largest French cities, with respective distances of $750 \mathrm{~km}$ and $570 \mathrm{~km}$. These routes represent a significant share of total long distance passenger traffic in France. Because of geographical, cultural and economic features, these routes attract a diversity of passengers, mainly business and leisure passengers, which probably explains the differentiation in available transport services. Three main passenger travel modes are offered on these links: rail, road (private car and carpooling) and air. ${ }^{3}$ The rail service, provided with the high speed train technology, allows for a real competition in terms of travel time between air and rail transport on these specific distances. Private car presents the advantage of a great flexibility in departure times and the recent emergence of the carpooling platforms offers a low cost option for traveling by car. We assume here that private car and carpooling are not relevant competing options for business passengers.

Most of the data on traffic, prices and marginal costs is provided by SNCF Réseau for one year, namely 2016. We use annual traffic data for one-way tickets on both links, for the two business and leisure segments. Note that rail traffic from servicemen, SNCF beneficiaries and concessions to large families are not included in these data as their favorable fare conditions are imposed by the State and make these passengers captive to the option of traveling with the rail mode. This sub-population corresponds to $8 \%$ of rail traffic or $4 \%$ of total traffic on these links. For every transport mode (except for private car) and the two main categories of passengers, the price measured in euros corresponds to the weighted average price paid by the different passengers. The values for marginal costs are computed as the sums of unit operating costs and unit tolls, on each link. Marginal costs are assumed to be the same for business and leisure transport services, as confirmed by the representatives of SNCF Réseau who provided the data used in this model. The price paid by one passenger traveling by car is computed as the sum of fuel and tolls expenses for one car (recovered from Viamichelin.com) divided by the average number of passengers seating in one car, set to 2.22 passengers, according to the Enquête Nationale Transports et Déplacements (2008).

All data available are gathered in Table 1. Only these data are used at the calibration stage. Given the similarities of data for the leisure segment on both markets, we provide and discuss the results of simulations for the Paris-Marseille market. For the business segment, we comment

emerge through tendering and franchising."

3 The rail mode is provided by one operator only, i.e., the French incumbent, SNCF. The air transport service is provided by different operators on the links we are considering here. However, the main French operator, i.e., AIR FRANCE, is largely dominant on these markets. We then consider that de facto there is only one air operator. The car sharing option is mainly offered by a new entrant called BlaBlaCar. We do not consider buses here as this mode were negligible on the two routes during the period under investigation. 
below the results from the Paris-Bordeaux market where the market share of the air mode is relatively high. ${ }^{4}$

Table 1: Data for the competition model

\begin{tabular}{|c|c|c|c|c|c|c|c|c|c|c|c|c|}
\hline \multirow{3}{*}{$\begin{array}{l}\text { Market } \\
\text { Passenger type }\end{array}$} & \multicolumn{6}{|c|}{ Paris - Marseille } & \multicolumn{6}{|c|}{ Paris - Bordeaux } \\
\hline & \multicolumn{3}{|c|}{ Leisure } & \multicolumn{3}{|c|}{ Business } & \multicolumn{3}{|c|}{ Leisure } & \multicolumn{3}{|c|}{ Business } \\
\hline & $\mathrm{MS}(1)$ & Price $^{(2)}$ & $\mathrm{MC}^{(3)}$ & MS & Price & $\mathrm{MC}$ & MS & Price & $\mathrm{MC}$ & MS & Price & $\mathrm{MC}$ \\
\hline Rail & $54.8 \%$ & 64.9 & 49.1 & $85.2 \%$ & 84.2 & 49.9 & $37.3 \%$ & 57.8 & 41.2 & $64.3 \%$ & 74.2 & 41.2 \\
\hline Air & $8.4 \%$ & 86.3 & 53.9 & $14.8 \%$ & 118.1 & 53.9 & $11.3 \%$ & 81.2 & 41.5 & $35.7 \%$ & 111.0 & 41.5 \\
\hline Car & $34.6 \%$ & 59.1 & & & & & $45.5 \%$ & 45.5 & & & & \\
\hline Car pooling & $2.2 \%$ & 44.3 & & & & & $5.9 \%$ & 33.3 & & & & \\
\hline
\end{tabular}

Notes: (1) MS means market share; (2) Prices are measured in Euros; (3) MC means marginal cost and is measured in Euros.

\section{A Model of Intermodal Competition}

Here we present a framework aimed at capturing intermodal competition between transport alternatives. We only consider the short-run price competition among transport operators assuming that they have previously defined their transport services. In other words we do not look at the intertemporal relation between the design of products and the pricing strategy. We first describe the demand side, and then characterize the determination of prices by operators involved in a Bertrand-Nash competition.

\subsection{Demand side}

We consider the choices made by potential passengers willing to travel on a link between two cities (for instance between Paris and Marseille) in terms of mode and service provided. Four transport options are available on the link: rail, air, personal car, car-pooling. The alternatives are characterized by a quality parameter and a price. In addition we assume the existence of an outside alternative: Instead of choosing one of the services offered to travel from Paris to Marseille, consumers may decide not to travel. Hence the total market size is defined as the number of consumers who would be potentially interested in making the trip.

The potential passengers for a one way trip on the link are heterogeneous. We consider two main categories in the passengers' population: Business and leisure passengers. There are potential passengers on the business and leisure markets who may either travel using one of the transport services supplied, or otherwise choose not to travel, which is herein the outside alternative. We are going to assume that business passengers use only the rail and air modes, whereas the leisure passengers can use any mode (rail, air, personal car, car-pooling). These two types of passengers differ by their own valuations for the characteristics of transport services and their own sensitivity to prices (our assumption that business passengers only use the air and rail modes amounts to imposing that their valuations for the two road options are extremely negative). In what follows, we account for these two types of passengers by considering two separate markets: The business market and the leisure market. In this way, the calibration procedure we follow produces two sets of parameters characterizing the different tastes and willingness-to-pay of the two groups of customers. In the sequel, we describe in details the leisure

4 Detailed results of simulations for the different markets are available upon request. 
market, adaptations to the business market are straightforward.

Assume that there are $N$ potential passengers on this market. Each consumer makes her choice among the alternatives in the following way: An alternative, or a product, is a combination of a transport mode and a service provided by a transport operator. Note that, for personal car alternative, the transport operator is the driver in her car. There are 5 alternatives, where alternative $j=0$ corresponds to the outside alternative (herein, OG) and the other four alternatives, corresponding to rail, air, personal car and carpooling, are denoted by $j=1, \ldots, 4$, in this order.

Consumers' utility depends on quality and prices. We attribute a quality index $\psi_{j}$ and a price $p_{j}$ to every alternative. The utility function of passenger $i$ associated with the alternative $j$ is given by:

$$
U_{i j}=V_{j}+\varepsilon_{i j}
$$

where the deterministic component $V_{j}$, defined as

$$
V_{j}=\psi_{j}-h p_{j},
$$

represents the mean utility level common to every passenger and the random component $\varepsilon_{i j}$ corresponds to the departure of passenger $i$ from the common utility level, specific to product $j$ , i.e., to the passenger $i$ 's unknown preferences for product $j$. Parameter $h$, which measures the rate of change between quality and price, is called the marginal utility of income. Since the quality and the price of the outside alternative are undefined, we assume that:

$$
V_{j}=0 \text { for } j=0
$$

We also assume a logit specification for the random preferences of the representative passenger. Therefore the market share of alternative $j(\forall j=0,1, \ldots, 4)$ is obtained as the logit probability:

$$
s_{j}=\frac{\exp \left(V_{j}\right)}{\sum_{k \geq 0} \exp \left(V_{k}\right)},
$$

and $N_{j}=s_{j} N$ is the number of passenger choosing alternative $j$. Note that if one observes the number of passengers that select one of the four transport modes, one does not know $N_{0}$, the number of individuals choosing not to travel. Hence we do not observe $N$ either.

Following Berry (1994), this specification yields the passenger demand function as:

$$
\ln \left(s_{j}\right)-\ln \left(s_{0}\right)=\psi_{j}-h p_{j} .
$$


Differentiating with respect to $p_{j}$ and noting that $\frac{\partial s_{0}}{\partial p_{j}}=-h s_{0} s_{j}$, we obtain the own price elasticities of demand as:

$$
\eta_{j}=h p_{j}\left(1-s_{j}\right) \text { for } j=1, \ldots, 4
$$

\subsection{Supply side}

We assume that the rail and air modes are each offered by a different firm taking as given the other alternatives and strategically choosing its prices so as to maximize its profit. By contrast, the operators on the road mode (personal car and carpooling) are not strategic actors; they simply set a price equal to their marginal cost.

The strategic decision of rail and air operators is described as follows. If $c_{j}$ is the marginal cost of providing the transport service by firm $j$ and if $K$ is a fixed cost, the profit function of firm $j$ is given by

$$
\pi_{j}=\left(p_{j}-c_{j}\right) q_{j}-K
$$

When the transport firms maximize their profit, they choose prices so that their margins, measured as the Lerner index, are equal to the willingnes-to-pay of their clients, which is measured as the inverse of the own price elasticity, that is to say, so that:

$$
\frac{p_{j}-c_{j}}{p_{j}}=\frac{1}{\eta_{j}} .
$$

It means that the firm prices the transport service so as to extract all the rent from the passenger.

However, a transport operator can be subject to some form of regulation and governance contraints or can attempt to protect its market share in the future. In that case, it might internalize part of the consumer surplus when choosing its prices, where the consumer surplus associated with alternative $j$ is given by:

$$
C S_{j}=\int_{0}^{q_{j}}\left(P(t)-p_{j}\right) d t
$$

where $P(t)$ is the inverse demand function. This transport firm now maximizes a weighted sum of its own profit and the consumer welfare, where the weight associated to the consumer welfare is denoted by $\mu_{j}$ and it is called the degree of price distortion associated to the mode $j$. The price $p_{j}$ now must satisfy the modified Lerner condition:

$$
\frac{p_{j}-c_{j}}{p_{j}}=\frac{1-\mu_{j}}{\eta_{j}}
$$

When $\mu_{j}=0$, we are back to the standard Lerner equation; when $\mu_{j}=1$, the firm fully 
internalizes the consumer welfare, and therefore sets a price equal to its marginal cost. ${ }^{5}$

More generally, this operator may pursue objectives other than short term profit maximization and this may be modeled in a variety of ways (e.g., a weighted average of multiple interests, such as enterprise's profit, taxpayers' benefit, and consumers surplus). (See Sappington and Sidak 2003.) We leave the choice of objective function as an empirical question and test different models. More specifically, as explained below, we assume that the airline maximizes its profit $\left(\mu_{2}=0\right)$, but allow $\mu_{1}$, the parameter associated with the first operator, to be positive. Besides, we also test a specification in which the railways firm maximizes a weighted sum of its own profit and its revenue (instead of consumer surplus). The outcome of those tests are presented and discussed in section 4.2.

\section{Calibration}

With the data available on the two links under consideration, we cannot carry an econometric estimation. Our objective is to proceed to a calibration of the main parameters of our model in order to derive reasonnable values to be used to run simulations and counterfactuals.

\subsection{Methodology}

Calibrating the model consists in solving the system of equilibrium equations in terms of the unknown parameters, which are the quality indexes for the four transport modes, i.e., $\left(\psi_{1}, \psi_{2}, \psi_{3}, \psi_{4}\right)$, the marginal utility of income, $h$, and the market size $N$. In the case where only the first operator (rail) maximizes a weighted sum of its profit and the consumer surplus, one also needs to evaluate the degree of price distortion $\mu \equiv \mu_{1}$. We assume that the second operator (air) maximizes its profit and that the two other operators (car and carpooling) just set their prices to their marginal costs.

Then we have to calibrate seven unknown variables $\left(\psi_{1}, \psi_{2}, \psi_{3}, \psi_{4}, h, N, \mu\right)$ with only six equations, which are:

$$
\begin{gathered}
p_{1}-c_{1}=\frac{1-\mu}{h\left(1-\frac{N_{1}}{N}\right)^{\prime}}, \\
p_{2}-c_{2}=\frac{1}{h\left(1-\frac{N_{2}}{N}\right)}, \\
\frac{N_{j}}{N}=\frac{\exp \left(\psi_{j}-h p_{j}\right)}{1+\sum_{k \geq 1} \exp \left(\psi_{k}-h p_{k}\right)} \quad \forall j=1, \ldots, 4 .
\end{gathered}
$$

5 Note that this is similar to a Ramsey-Boiteux problem, where a regulated firm maximizes the social welfare, with a Lagrange multiplier associated to its budget constraint defined as $\lambda_{j}=\mu_{j} /\left(1+\mu_{j}\right)$. 
It is straightforward to observe that the unknown parameters $\left(\psi_{1}, \psi_{2}, \psi_{3}, \psi_{4}, h, N\right)$ can be expressed as some explicit functions of $\mu$.

The calibration takes place in two steps. First, we solve the two first equations (11) and (12) for $h$ and $N$ as functions of $\mu$. Second, given $h(\mu)$ and $N(\mu)$, we solve the four demand equations (13) for the four unknowns $\psi_{j}$.

\subsection{Application}

Here we apply this algorithm to solve for the unknown parameters when the equilibrium on each of the four markets under investigation, i.e., Paris - Marseille and Paris - Bordeaux, leisure and business, is characterized by a level of market shares, marginal costs and prices as they are gathered in Table 1.

As explained in Section 3.2, various models are tested with respect to the first operator's strategy (i.e., the rail monopoly). First, we try to calibrate the model under the assumption that the two first operators, i.e., rail and air, are maximizing their profits $(\mu=0)$. Solving the equilibrium equations (11), (12), and (13), we have not been able to find economically meaningful values for the parameters. We also test a specification in which the railways firm maximizes a weighted sum of its own profit and its revenue, but the magnitudes of the parameters of interest were highly unreasonable; we discarded this specification as it did not fit the data describing our markets. Eventually, a satisfying calibration is achieved with the model presented in Section 3.2, in which the first operator maximizes a weighted sum of its profit and the consumer surplus. In this setting, we solve the equilibrium equations for different values of the degree of price distorsion. It turns out that any value of $\mu$ smaller than 0.4 or larger than 0.7 ended in unrealistic values for the other parameters. Finally, our computations have shown that the best value of $\mu$ is close to 0.55 .

Those results make sense in view of the fact that the average train tickets are too low compared to what can be predicted by a static model in which the rail incumbent (the first operator here) would only maximize its short-term profit. In other words, the incumbent's prices are clearly too low compared to marginal costs to be compatible with reasonable assumptions on price elasticities. Two main hypotheses can be put forward to explain the low average prices of the incumbent. First, it could be the result of a downward pressure on prices exerted by the State in the framework of a regulation of the railway supposed to prevent a too high pricing by the monopoly. ${ }^{6}$ Second, it is the outcome of a dynamic game integrating the reaction of other players, likely to later penalize the incumbent if it practices higher prices. ${ }^{7}$ These players could be the regulator, new potential entrants, but also different "stakeholders" as railway workers or regional authorities. In particular, the incumbent can seek to maintain a large volume of passengers, via an aggressive tariff policy, in order to seek to anticipate and prevent a reaction from the regulator that has several possible modes of action such as the opening to competition with the entry of a low-cost operator. The strategy of the incumbent operator would be similar to a so-called limit

6 In a report on the state of the French rail system, Spinetta (2018) provide evidence in support of our finding. He writes: "According to GoEuro, the average price in France would be 7.8 euros for 100 kilometers, against 29.7 euros in Denmark, 28.6 euros in Switzerland, 24 euros in Austria. Italy and Germany would also have higher tariffs."

7 With respect to this point, note that Nash, Crozet, Nilsson and Link (2016) "mention that the historical operator has developed a strategy to prevent any potential price war from being initiated by a new entrant, which involves not only a very smart yield-management pricing system but also special 'low-cost' HSR services." 
pricing strategy (See Milgrom and Roberts, 1982, and Fudenberg and Tirole, 2000.). The maximization of a weighted sum of profit and consumer surplus, used in our model, can indeed account for these possible conducts and constraints.

Using this value for the degree of price distorsion, the parameters of interest resulting from equilibrim equations (11), (12), and (13) are gathered in Table 2 below.

Table 2: Calibrated values for the parameters of interest

\begin{tabular}{|c|c|c|c|c|c|c|c|c|}
\hline Market & \multicolumn{4}{|c|}{ Paris - Marseille } & \multicolumn{4}{|c|}{ Paris - Bordeaux } \\
\hline Passenger type & \multicolumn{2}{|c|}{ Leisure } & \multicolumn{2}{|c|}{ Business } & \multicolumn{2}{|c|}{$\begin{array}{l}\text { Leisure } \\
\end{array}$} & \multicolumn{2}{|c|}{ Business } \\
\hline & Elasticity & Quality & Elasticity & Quality & Elasticity & Quality & Elasticity & Quality \\
\hline Rail & -1.6 & 1.7 & -1.0 & 0.7 & -1.3 & 0.7 & -0.9 & 0.7 \\
\hline Air & -2.7 & 0.5 & -1.8 & -0.5 & -2.0 & 0.2 & -1.6 & 0.7 \\
\hline Car & -1.5 & 1.0 & & & -0.9 & 0.6 & & \\
\hline Car pooling & -1.4 & -2.2 & & & -0.9 & -1.8 & & \\
\hline
\end{tabular}

The values of elasticities are consistent with previous findings. (See Oum et al., 1990, Bureau of Transport and Regional Economics, 2003 and Ivaldi and Vibes, 2008.) As expected they are higher for leisure passengers than for business passengers.

The quality parameters reflect the objective characteristics of transport modes such as frequency, distribution of frequencies between peak and off-peak hours, comfort and speed, but also unobserved characteristics. Observe that the quality of the rail mode is somehow higher than the one of the air mode, which may be reflecting the advantages in terms of confort of a high speed train seat and the convenience to arrive in a city center. Note also that frequencies for the rail and air modes are both very high (14 and 24 departures per day respectiveley on the Paris-Marseille link), and that the door to door travel time is very similar for these two modes.

\section{Simulations}

Using the calibrated parameters and the structure of the model, we are in the position to simulate various scenarios of opening to competition on the rail market. For each scenario, we derive an estimate of its impact on the consumer surplus, the prices, the market share and the profit of the various operators, and finally the amount of tolls collected to finance the rail infrastructure. These scenarios are depending on factors that can decisevely affect the entry on the rail market.

\subsection{The drivers of entry}

The three main drivers of entry are now presented and discussed.

\subsubsection{The operators' costs}

Whatever the method of opening up to competition, the assumption is that it should result in lower operational costs for railway operators. In case of opening to competition of the market, the new entrant usually benefits from variable costs (excluding tolls) lower than those of the incumbent, which responds to the entry by reducing its own costs. In case of opening to competition for the market, the competition of operators via the call for tenders launched by the 
regulator (to choose the operator that will deliver the transport service) provides an incentive to a scaling down of operational costs.

Besides operational costs, the level of access charges can also affect the decision of entry. However, as it is an instrument in the hand of the regulator, it should not affect the choice of type of competition.

\subsubsection{The quality of operators' supply}

We previously introduced the parameters of quality which mainly reflect the combination of characteristics of various transport modes. Quality cannot be updated, upgraded or enhanced easily, continuously or instantaneously. It depends on the effort level of investment in the rolling stock to ensure a certain level or reliability or confort, in the commercial organization to provide an efficient assistance to customers, or in the marketing strategies to propose adequate tariffs. Each operator choses the level of these efforts and so affects the quality level of transport servcies.

However, the latter is not fully in the hand of operators. It is well known that it is also highly determined by the frequency of trains and their distribution according to the hour of the day or the day of the week. In case of opening up to competition in the market, by allowing the new entrant more or less easy access to the network, by prioritarily allocating the "best" train paths to the incumbent, by making decisions regarding the management of delays and the quality of interconnections, the regulator is likely to influence to a great extent the quality of railway operators. Hence there is a great diversity of possible scenarios as to the change in the quality of the incumbent's offer as a result of opening up to competition and as to that of the new entrant. We therefore consider various scenarios reflecting this wide range of possible changes. In case of opening to competition for the market, however, there is less uncertainty about the evolution of the quality of the rail operator's offer since one can either focus on a scenario where the quality is maintained at its current level or is enhanced at a level required in the call for tenders launched by the regulator to choose the operator that will deliver the transport service.

\subsubsection{Change in the degree of price distortion}

The working of competition should incentivize the incumbent to change its objective to be closer to a pure maximization of its profit in the short term, in particular because the openess of the market will probably be accompanied by price deregulation and a relaxation of behavior aimed at anticipating such an opening. Hence we could expect a lessening in the degree of price distortion (that is, a decrease in $\mu$ ). On the contrary, if one fears that the entry of competitors on the market could encourage the incumbent to engage in a predatory pricing strategy to oust its competitor, or if the regulator wishes to maintain some pressure on the tariffs or its requirements for rail accessibility, then a certain distortion of tariffs should be at least partially maintened.

Insofar as the data available do not allow to understand precisely the reasons for the downward pressure on prices observed in the status quo, one cannot make reliable predictions of the way in which competition will affect the tariff distortion. Consequently, we carry out tests of sensitivity to a change in the degree of price distortion. Nevertheless, it should be noted that a change in tariff distortion is more plausible in the short term in the case of opening to competition in the market than in the case of opening for the market. Indeed, in the latter case, the regulator could include, in the call for tenders, constraints that incorporate the consumer surplus.

\subsection{Characterization of the status quo}

We first discuss in more detail the statusquo. This provides a benchmark to discuss the 
other scenarios, in particular in terms of levels and changes for the main indicators like the consumer surplus or the profits of operators. Recall that the results in section 5.3 et 5.4 below are reported for the leisure segment of the Paris-Marseille market. The results for business for the Paris-Bordeaux market are then briefly discussed. The values characterizing the status quo are given in column 1 of Table A1. ${ }^{8}$

To give an idea of the impact of the degree of price distortion, we simulate what would be the status quo if the distortion on prices is lessened until it fully disappears. The results are presented on the last three columns of Table A2. We observe that the prices of the incumbent would then increase by $27 \%$ and its profit by around $20 \%$. This sharp rise in rail prices and profits would be to the detriment of the transport passenger as the consumer surplus decreases by $18 \%$ and the contribution of tolls to infrastructure funding would be reduced by $37 \%$. Note that the prices for the air mode does not change much as they decrease by less than one percent.

This constitutes an important finding of our analysis: If the opening up to competition ends up to diminish the degree of price distortion, by a relaxation of the tariff moderation for instance, it risks penalizing the consumer strongly.

\subsection{Opening to competition in the market}

For reasons explained in section 5.1.1, the scenarios for the opening to competition in the market are based on the assumption that the new entrant benefits from variable costs (i.e., operating expenses excluding tolls) $30 \%$ lower than those of the incumbent, which responds to the entry of a competitor in reducing its own costs by $10 \% .{ }^{9}$ Considering other scenarios on the levels of costs of the two competitors does not provide more information on the outcome of the opening to competition.

Thanks to the flexibility of the logit model, we modifiy our basic model to account for a new entrant which is equivalent as considering a new product. We do so by adopting a nested logit model which is presented in Appendix 1. It requires to calibrate the degree of correlation among the different alternatives, which is also explained in the appendix.

The new entrant maximizes its short-term profit. With regard to the incumbent operator, the most plausible assumption is that, after the opening to competition in the market, it would also seek to maximize its short term profit. As previously discussed, the incumbent operator today maximizes a weighted sum of its profit and the consumer surplus weighted by the degree-ofprice-distortion parameter $\mu$ that reflects the existence of different sources of tariff pressures like price regulation, political and social environement, or long-term strategy. One can expect that the opening to competition in the market could lessen the strengths of these tariff constraints over time though. For this reason we simulate scenarios for four different values of the degree of price distortion, with values ranging from $100 \%$ (which correspond to the status quo) to $0 \%$ (which corresponds to the disappearance of any tariff pressure) with $66 \%$ et $33 \%$ as intermediate cases.

To complete the scenarios, we need to define the quality levels of the two operators. To do

8 All tables are gathered in Appendix 2 at the end of the text.

9 A level of $30 \%$ cost efficiency for an entrant is supported by many experts. See for instance MVA Consultancy and The Institute for Transport Studies (2011). In a more recent study, Rasmussen, Wheat and Smith (2016) assess that open access operators in the U.K. would benefit from significantly lower costs, up to almost 30\%. Nevertheless, they do not specify the origin of this advantage, which seems closely linked to the regulatory framework: In the U.K., franchised operators pay higher tolls, have to take back the existing staff and, for those which are profitable, pay additional dividends to the State. New operators in open access escape all these constraints. In the absence of further refinement, the simulations presented here are based on ad hoc assumptions about cost reductions. This is why we consider $10 \%$ or $30 \%$ cost efficiency depending on the scenario. 
so, we first consider four distinct quality levels. The quality level of reference is by definition the quality parameter of the historical operator obtained by calibration of the model. It is referred as level " $100 \%$ " in our simulations, since it corresponds to $100 \%$ of the quality currently available. The other quality levels correspond to lower quality levels. The level of quality "80\%" (respectively " $50 \%$ " and " $10 \%$ ") is defined in such a way that, starting from the status quo and all things being equal (that is to say without changing prices or other parameters of the model), the incumbent's market share decreases to $80 \%$ (respectively $50 \%$ and $10 \%$ ) from its current level.

Second we combine these quality levels to design asymmetric scenarios where the incumbent keeps an advantage in terms of quality compared to the entrant, and symmetric scenarios where both operators achieve the same levels of quality. The results for the first set of scenarios are reported in Table A2a and for the second set in Table A2b.

Before commenting the results, let us look at the different forces at stake in the changes in prices. First, assuming that the opening to competition is accompanied with lower operating costs of rail operators, these efficiency gains are mechanically translated into a downward effect on prices. Second, assuming that the competition in the market is accompanied by a full relaxation of price distortions, this change in the constraints weighing on the pricing strategy of the rail incumbent has an upward effect on prices. Third, when moving from a monopoly situation to competition, the incumbent is submitted to a competitive pressure from its competitor, which tends to decrease its price. Fourth, while we consider an overall increase in total railway quality in all the simulated scenarios, the individual quality of each operator's offer remains at most equal to that of the incumbent today. Hence a lower individual quality level has a downward effect on prices. Simulating the different scenarios is then the only way to obtain the equilibrium prices that result from the combination of these conflicting forces.

This drives us to the main result of our analysis on the opening to competition in the market: Whatever the scenario considered, if opening to competition leads to a total suppression of the price distortion (that is, $\mu=0$ ), the incumbent's prices increase. Tables $2 \mathrm{a}$ and $2 \mathrm{~b}$ indeed show that the price increase is comprised between $8 \%$ (in a symmetric scenario where each of the two operators has a quality of 50\%) and 22\% (a highly asymmetric scenario in which the rail incumbent keeps its current level of quality).

What about the market shares of rail operators? In the highly asymmetrical case where the incumbent maintains its quality level at the status quo and the new entrant has only a $10 \%$ quality level, the market share of the new entrant is of the order of magnitude of $1 \%$ of the total market of potential passengers and $2 \%$ of actual passengers. This situation raises the question of the longterm viability of this scenario. Now, in the symmetric scenarios where the two operators have a similar level of quality, their market share will be approximately $15 \%$ of potential travelers when the quality is fixed at $80 \%$ of the status quo level.

Figure 1 in Appendix 3 summarizes the other main findings that one can draw from the reading of Tables $2 \mathrm{a}$ and $2 \mathrm{~b}$ when the degree of price distortion is set to $0 \%$. First, in some cases, the consumer surplus decreases which means that the passengers do not benefit from the improvement in the quality of the rail offer resulting from the diversification of the supply following from the multiplication of the number of operators. Second, the total amount of access charges collected decreases as a result of the contraction of the supply due to the price increase, itself being the consequence of the full relaxation of price distortions. The only exception is the case of a symetric case with $80 \%$ quality for both operators, and to a lesser extent in a asymetric scenario where the incumbent maintains its quality level and the new entrant is present with a quality of $50 \%$. Third, the effect on the profit of rail operators is strongly positive although this increase essentially benefits the new entrant much more than the incumbent. 
These conclusions heavily depend on the assumption of no price distortion, and are even reversed if the degree of price distortion is maintained at its current level. The results presented in Table $\mathrm{A} 2 \mathrm{a}$ and $2 \mathrm{~b}$ show that maintaining a high degree of price distortion makes it possible to ensure a positive change in the consumer surplus and the amount of access charges raised to the detriment of the profit of rail operators. The question is to evaluate whether scenarios with positive degrees of price distortion are realistic when the market is opened to competition.

Summing up, the opening to competition in the market is highly uncertain in the sense that it strongly depends on whether the price distortion will be removed as well as on the quality of the new entrant which, in turn, is largely function of the level of access to the train paths it will obtain. In many cases, the effect of the opening to competition is relatively weak for the passenger or even negative if the price distortion disappears. It is mainly a transfer of profit from the incumbent to the new entrant. Since the two operators do not offer sufficiently high quality, the downward pressure on prices caused by competition and the fall in costs are not enough to offset the relaxation of price distortions. In other words, maintaining a price distortion is necessary in order to avoid a deterioration of the consumer surplus.

\subsection{Opening to competition for the market}

The scenarios for opening to competition for the market is modeled on the assumption that, following a call for tenders, the regulator is able to select an operator with operating costs $10 \%$ lower than those of the incumbent with a level of quality close to that of the status quo. A variant with costs lower of $30 \%$ and lower quality is also presented in Table A3 of Appendix 2. It is assumed here that the structure and level of access charges are left unchanged from the status quo.

When responding to the tender launched by the regulator to select the entity that will provide the transport service on a given market, each candidate operator indicates a level of subsidy that it requests if it anticipates that the profits generated will not be sufficient to cover the operating costs, or on the contrary, the lump sum that it is ready to offer to access the market. Our model does not allow us to study in detail how this upstream competition effectively work, and therefore does not allow us to evaluate the direct transfers that can be made between the operator and the regulator, part of which could be used to finance the fixed costs of the infrastructure. In what follows, when we focus on the financing of infrastructure, we only derive the levels of access charges that each scenario of opening to competition yields. How the financing of infrastructure impacts the mode of opening the rail market to competition is left for further research.

In the case of an opening to competition for the market, it is not unconcievable to assume that the regulator might design the tender so as to impose constraints that would favor the consumer and therefore would allow a relative maintenance of the regulatory pressure on prices. The regulator could even choose a regulation more favorable to the consumers by increasing the tariff distortion. The rationale to do so is that, to some extent, the degree of price distortion informs how efficiencies related to the reduction of operational costs are shared between the passengers and the rail operator. In this perspective we propose to consider 6 scenarios of change in the degree of price distortion: Increase to $125 \%$, increase to $110 \%$, maintenance of the status quo at $100 \%$, transition to $67 \%$ and $33 \%$ of the status quo, disappearance of any tariff distortion at $0 \%$. The results of these scenarios are displayed in Table A3.

These results confirm the intuition. If the degree of price distortion is maintained at its current level (i.e., $100 \%$ ), i.e. if the rail operator continues to maximize a weighted sum of its profit and the consumer surplus with a relative weight which remains identical to that of the status quo, 
efficiency gains naturally translate into lower prices. More precisely, prices decrease by $3 \%$ in the $10 \%$ cost-savings scenario and by $9 \%$ in the $30 \%$ cost-saving scenario; respectively consumer surplus slightly increases by $2 \%$ and $+8 \%$, the operator's profit increases by $7 \%$ and $21 \%$, and the revenus from the access charges increase by 5\% and 15\%. (See columns 5 and 11 of Table A3).

Figure 2 in Appendix 3 summarizes some of the main findings that can be drawn from the inspection of Table A3. It displays the changes in the consumer surplus, the profit of the railway operator and the contribution of access charges to the financing of fixed costs infrastructure.

By lessening the degree of price distortion, we change the way in which the efficiency gains are distributed among the different actors. The higher the price distortion (i.e., the weight placed on the consumer surplus), the lower the prices, and therefore the more favorable the change for passengers. Note that, since the amount of access charges collected is proportional to the volume of rail traffic, it varies in the opposite direction of rail prices, and therefore also increases with the degree of price distortion, while conversely, the profit of the rail operator evolves mechanically in the opposite direction.

When the degree of price distorsion increases relative to the status quo (for example when it reaches $125 \%$ ), the consumer surplus increases sharply by $9 \%$ in the scenario with a reduced cost of $10 \%$. So does the contribution of access charges to the financing of infrastructure (+ 18\%). On the contrary, the profit of the railway operator decreases by $12 \%$. In the opposite extreme case where the opening to competition is accompanied by a removal of any price distortion, the consumer surplus and the access charges falls sharply from the status quo (by 16\% and 33\% respectively). Even in the most favorable scenario of a $30 \%$ reduction in operating costs, the efficiency gains of rail operator can not compensate the prices increase.

\subsection{Comparison of types of opening up to competition}

Table A4 provide a summary of some typical and relevant scenarios.

A first conclusion is that the competition can bring benefits to the passenger only if the distortion of prices is maintained on the incumbent operator. In the case of competition for the market, it is conceivable to explicitly impose, in the call for tenders, this constraint of price distortion as a prerequisite for the operator to be selected to provide the transport service. By contrast, competition in the market seems to inevitably lead to a reduction of this "price distortion".

A second conclusion is that the benefit for the passenger of opening up to competition in the market appears more uncertain: It becomes positive when the quality of the supply remains sufficient, and a significant price distortion is maintained on the historical operator (at least at a level of $66 \%$ according to our simulations reported in Table A4). The loss for the passenger becomes important when the price distortion is totally relaxed or when the diversification of the offer is very low with a new entrant providing only a low level of quality (a case reported in the last column of Table A4). Note that the fourth and fifth columns of Table A4 are relatively close to the "Italian" case where the new entrant and the incumbent have relatively close train path amounts, while the last column reflects more the "German" case, where the new entrant only gets a very limited number of train paths.

\subsection{The case of the business segment}

Table A5 provides the same information as Table A4 but for the business segment on the link between Paris and Bordeaux. It is straightforward to observe that the values in the two tables 
are very similar. In fact, if on the leisure segment there are more competitors, as a matter of fact only two are strategic competitors: air and rail. Then it is similar to the situation of the business segment since these are the only competitors here also. This mainly explains why the figures on the two tables are very close. Hence the lessons drawn from Table A4 apply here as well.

\section{Concluding remarks}

To our knowledge, the analysis carried out here constitutes the first simulation work providing a quantitative comparison of the methods of opening up to competition for versus in the market for the railway sector. The objective is to contribute to the debate on the modalities of opening to competition by bringing some quantified elements. Like any modeling work however, it does not have the ambition to answer all the questions, in particular it does not address many questions pertaining to the availability of rolling stocks, the management of train stations or the design of safety rules that could impact the process of opening to competition the rail services. We leave these questions for future research. 


\section{Appendix 1: The nested logit model for the new entrant case}

Here we extend our demand model using a nested logit to allow for a new alternative $j=5$, called the new entrant, to appear in the same "group" or nest as the alternative 1, i.e., regular rail. The value of quality index of the new entrant is denoted by $\psi_{5}$.

As before, the utility function associated with alternative $j$ is written as:

$$
U_{i j}=V_{j}+\varepsilon_{i j}
$$

We assume here that the error terms for the two rail alternatives, namely the rail incumbent and the new entrant, are correlated. Namely, they are specified as:

$$
\varepsilon_{i 1}=v_{i, r a i l}+(1-\sigma) v_{i 1}
$$

and

$$
\varepsilon_{i 5}=v_{i, \text { rail }}+(1-\sigma) v_{i 5}
$$

where $v_{i, \text { rail }}$ is a common random component while $v_{i 1}$ and $v_{i 5}$ are specific random components. These three components are assumed to be independently distributed so that each of them, as well as the errors terms $\varepsilon_{i j}$, follows a standard extreme value distribution. The parameter $\sigma$ gives a measure of the degree of correlation between alternatives belonging to the group "rail". It lies between 0 and 1 . The higher $\sigma$, the higher the correlation between alternatives in the rail group.

Under these assumptions, the probability of choosing alternative $j$ is therefore:

$$
s_{j}=\frac{\exp \left(V_{j}\right)\left(s_{j \mid \text { train }}\right)^{\sigma}}{\left(\sum_{k=2,3,4} \exp \left(V_{k}\right)\right)+\left(\sum_{k=1,5} \exp \left(\frac{V_{k}}{1-\sigma}\right)\right)^{1-\sigma}} \text { for } j \in\{1,5\}
$$

and

$$
s_{j}=\frac{\exp \left(V_{j}\right)}{\left(\sum_{k=2,3,4} \exp \left(V_{k}\right)\right)+\left(\sum_{k=1,5} \exp \left(\frac{V_{k}}{1-\sigma}\right)\right)^{1-\sigma}} \text { for } j \in\{2,3,4\} \text {, }
$$

where 


$$
s_{j \mid r a i l}=\frac{\exp \left(\frac{V_{j}}{1-\sigma}\right)}{\sum_{k=1,5} \exp \left(\frac{V_{k}}{1-\sigma}\right)}
$$

is the probability of choosing alternative $j$ conditional on having chosen the rail mode.

Under this specification, we derive the demand functions

$$
\ln \left(s_{j}\right)-\ln \left(s_{0}\right)=\psi_{j}-h p_{j}+\sigma \ln \left(s_{j \mid r a i l}\right) \text { for } j=1,5,
$$

and

$$
\ln \left(s_{j}\right)-\ln \left(s_{0}\right)=\psi_{j}-h p_{j} \text { for } j=2,3,4 \text {. }
$$

One therefore obtains the following own price elasticities of demand:

$$
\eta_{j}=h p_{j}\left(1-s_{j}\right)+\frac{\sigma}{1-\sigma} h p_{j}\left(1-s_{j \mid \text { train }}\right) \text { for } j=1,5
$$

and

$$
\eta_{j}=h p_{j}\left(1-s_{j}\right) \text { for } j=2,3,4 \text {. }
$$

For fixed $\sigma$ and $\mu$, the equilibrium is fully characterized by the equations:

$$
\frac{p_{1}-c_{1}}{p_{1}}=\frac{1-\mu}{\eta_{1}}, \frac{p_{2}-c_{2}}{p_{2}}=\frac{1}{\eta_{2}} \text { and } \frac{p_{5}-c_{5}}{p_{5}}=\frac{1}{\eta_{5}} .
$$

The system with three unknown, $p_{1}, p_{2}$, and $p_{5}$ can be solved numerically.

In our simulations, we will fix the value of $\sigma$ at 0.3 . 


\section{Appendix 2: Tables}

Table A1: Impact of a change in the degree of price distortion on the status quo

\begin{tabular}{|c|c|c|c|c|c|}
\hline & & \multicolumn{4}{|c|}{ Degree of Price Distortion } \\
\hline & & $100 \%$ & $66 \%$ & $33 \%$ & $0 \%$ \\
\hline \multirow{2}{*}{ Incumbent } & Marginal cost & \multicolumn{4}{|c|}{24} \\
\hline & Access charge & \multicolumn{4}{|c|}{25} \\
\hline \multirow{2}{*}{ Prices $(€)$} & Rail & 68 & 75 & 81 & 87 \\
\hline & Air & 86 & 86 & 86 & 86 \\
\hline \multirow{2}{*}{ Change in prices } & Rail & 0 & $+9 \%$ & $+18 \%$ & $+27 \%$ \\
\hline & Air & 0 & 0 & 0 & 0 \\
\hline \multirow{5}{*}{ Market shares } & Rail & $28 \%$ & $24 \%$ & $21 \%$ & $18 \%$ \\
\hline & Air & $5 \%$ & $5 \%$ & $5 \%$ & $5 \%$ \\
\hline & Car & $19 \%$ & $20 \%$ & $21 \%$ & $22 \%$ \\
\hline & Car sharing & $1 \%$ & $1 \%$ & $1 \%$ & $1 \%$ \\
\hline & No travel & $47 \%$ & $49 \%$ & $51 \%$ & $53 \%$ \\
\hline \multirow{5}{*}{$\begin{array}{l}\text { Change in } \\
\text { market shares }\end{array}$} & Rail & 0 & $-14 \%$ & $-26 \%$ & $-37 \%$ \\
\hline & Air & 0 & $+5 \%$ & $+10 \%$ & $+14 \%$ \\
\hline & Car & 0 & $+6 \%$ & $+10 \%$ & $+14 \%$ \\
\hline & Car sharing & 0 & $+6 \%$ & $+10 \%$ & $+14 \%$ \\
\hline & No travel & 0 & $+6 \%$ & $+10 \%$ & $+14 \%$ \\
\hline \multirow{2}{*}{ Profits (en M€) } & Rail & 15 & 17 & 18 & 18 \\
\hline & Air & 4 & 4 & 5 & 5 \\
\hline \multirow{2}{*}{$\begin{array}{l}\text { Change in } \\
\text { profits }\end{array}$} & Rail & 0 & $+14 \%$ & $+21 \%$ & $+23 \%$ \\
\hline & Air & 0 & $+6 \%$ & $+10 \%$ & $+14 \%$ \\
\hline \multicolumn{2}{|l|}{ Access fees $(\mathrm{M} €)$} & 16 & 13 & 12 & 10 \\
\hline \multicolumn{2}{|c|}{ Change in access fees } & 0 & $-14 \%$ & $-26 \%$ & $-37 \%$ \\
\hline \multicolumn{2}{|c|}{ Consumer surplus } & 64 & 60 & 56 & 53 \\
\hline \multicolumn{2}{|c|}{ Change in consumer surplus } & 0 & $-7 \%$ & $-13 \%$ & $-18 \%$ \\
\hline
\end{tabular}

Notes: The unit M€ means millions of Euros. 
Table A2a: Opening to competition in the market: Simulation results for the asymmetric scenarios

\begin{tabular}{|c|c|c|c|c|c|c|c|c|c|c|c|c|c|}
\hline \multirow{2}{*}{ Marginal cost } & Rail entrant & \multicolumn{12}{|c|}{17} \\
\hline & Rail incumbent & \multicolumn{12}{|c|}{21} \\
\hline Access charge & & \multicolumn{12}{|c|}{25} \\
\hline \multirow{2}{*}{ Quality level } & Rail entrant & \multirow{2}{*}{\multicolumn{4}{|c|}{$\begin{array}{c}10 \% \\
100 \%\end{array}$}} & \multirow{2}{*}{\multicolumn{4}{|c|}{$\begin{array}{c}50 \% \\
100 \%\end{array}$}} & \multirow{2}{*}{\multicolumn{4}{|c|}{$\begin{array}{l}50 \% \\
80 \%\end{array}$}} \\
\hline & Rail incumbent & & & & & & & & & & & & \\
\hline \multicolumn{2}{|c|}{ Degree of price distortion } & $100 \%$ & $66 \%$ & $33 \%$ & $0 \%$ & $100 \%$ & $66 \%$ & $33 \%$ & $0 \%$ & $100 \%$ & $66 \%$ & $33 \%$ & $0 \%$ \\
\hline \multirow{3}{*}{ Prices $(€)$} & Rail entrant & 64 & 64 & 64 & 64 & 66 & 67 & 67 & 68 & 67 & 67 & 68 & 68 \\
\hline & Rail incumbent & 66 & 72 & 78 & 84 & 64 & 69 & 74 & 79 & 62 & 68 & 72 & 77 \\
\hline & Air & 86 & 86 & 86 & 86 & 86 & 86 & 86 & 86 & 86 & 86 & 86 & 86 \\
\hline \multirow{2}{*}{ Change in prices } & Rail & $-3 \%$ & $+6 \%$ & $+14 \%$ & $+22 \%$ & $-7 \%$ & $+1 \%$ & $+9 \%$ & $+15 \%$ & $-9 \%$ & $-1 \%$ & $+6 \%$ & $+12 \%$ \\
\hline & Air & 0 & 0 & 0 & 0 & 0 & 0 & 0 & 0 & 0 & 0 & 0 & 0 \\
\hline \multirow{6}{*}{ Market shares } & Rail entrant & 1 & 1 & 1 & 1 & 7 & 8 & 8 & 9 & 8 & 9 & 9 & 9 \\
\hline & Rail incumbent & 29 & 25 & 22 & 19 & 28 & 24 & 21 & 18 & 22 & 19 & 17 & 14 \\
\hline & Air & 5 & 5 & 5 & 5 & 4 & 5 & 5 & 5 & 5 & 5 & 5 & 5 \\
\hline & Car & 19 & 20 & 21 & 22 & 18 & 18 & 19 & 20 & 19 & 19 & 20 & 21 \\
\hline & Car sharing & 1 & 1 & 1 & 1 & 1 & 1 & 1 & 1 & 1 & 1 & 1 & 1 \\
\hline & No travel & 45 & 48 & 50 & 52 & 42 & 44 & 46 & 47 & 45 & 47 & 48 & 49 \\
\hline \multirow{5}{*}{$\begin{array}{l}\text { Change in market } \\
\text { shares }\end{array}$} & Rail incumbent & $+4 \%$ & $-10 \%$ & $-23 \%$ & $-33 \%$ & $-2 \%$ & $-15 \%$ & $-26 \%$ & $-36 \%$ & $-20 \%$ & $-31 \%$ & $-41 \%$ & $-49 \%$ \\
\hline & Air & $-3 \%$ & $+3 \%$ & $+7 \%$ & $+11 \%$ & $-9 \%$ & $-5 \%$ & $-1 \%$ & $+2 \%$ & $-3 \%$ & 0 & $+3 \%$ & $+6 \%$ \\
\hline & Car & $-3 \%$ & $+3 \%$ & $+7 \%$ & $+11 \%$ & $-9 \%$ & $-5 \%$ & $-1 \%$ & $+2 \%$ & $-3 \%$ & 0 & $+3 \%$ & $+6 \%$ \\
\hline & Car sharing & $-3 \%$ & $+3 \%$ & $+7 \%$ & $+11 \%$ & $-9 \%$ & $-5 \%$ & $-1 \%$ & $+2 \%$ & $-3 \%$ & 0 & $+3 \%$ & $+6 \%$ \\
\hline & No travel & $-3 \%$ & $+3 \%$ & $+7 \%$ & $+11 \%$ & $-9 \%$ & $-5 \%$ & $-1 \%$ & $+2 \%$ & $-3 \%$ & 0 & $+3 \%$ & $+6 \%$ \\
\hline \multirow{4}{*}{ Profits (en M€) } & Rail entrant & 0 & 1 & 1 & 1 & 5 & 5 & 6 & 6 & 5 & 6 & 6 & 7 \\
\hline & Rail incumbent & 15 & 18 & 19 & 19 & 13 & 15 & 16 & 16 & 10 & 11 & 12 & 12 \\
\hline & Rail & 16 & 18 & 19 & 20 & 18 & 20 & 21 & 22 & 15 & 17 & 18 & 19 \\
\hline & Air & 4 & 4 & 4 & 5 & 4 & 4 & 4 & 4 & 4 & 4 & 4 & 4 \\
\hline \multirow{2}{*}{ Change in profits } & Rail incumbent & $+4 \%$ & $+19 \%$ & $+26 \%$ & $+28 \%$ & $-13 \%$ & $-1 \%$ & $+5 \%$ & $+7 \%$ & $-35 \%$ & $-26 \%$ & $-21 \%$ & $-20 \%$ \\
\hline & Rail & $+7 \%$ & $+22 \%$ & $+30 \%$ & $+32 \%$ & $+19 \%$ & $+35 \%$ & $+44 \%$ & $+49 \%$ & $+1 \%$ & $+14 \%$ & $+22 \%$ & $+26 \%$ \\
\hline \multicolumn{2}{|c|}{ Access fees $(\mathrm{M} €)$} & 17 & 15 & 13 & 11 & 19 & 18 & 16 & 15 & 17 & 15 & 14 & 13 \\
\hline \multicolumn{2}{|c|}{ Change in access fees } & $+7 \%$ & $-7 \%$ & $-19 \%$ & $-29 \%$ & $+24 \%$ & $+13 \%$ & $+3 \%$ & $-4 \%$ & $+8 \%$ & $-1 \%$ & $-9 \%$ & $-15 \%$ \\
\hline \multicolumn{2}{|c|}{ Consumer surplus } & 67 & 62 & 58 & 55 & 72 & 68 & 65 & 63 & 67 & 64 & 61 & 59 \\
\hline \multicolumn{2}{|c|}{ Change in consumer surplus } & $+4 \%$ & $-4 \%$ & $-9 \%$ & $-14 \%$ & $+13 \%$ & $+7 \%$ & $+2 \%$ & $-2 \%$ & $+4 \%$ & $0 \%$ & $-4 \%$ & $-8 \%$ \\
\hline
\end{tabular}

Notes: The unit M€ means millions of Euros. 
Table A2b: Opening to competition in the market: Simulation results for the symmetric scenarios

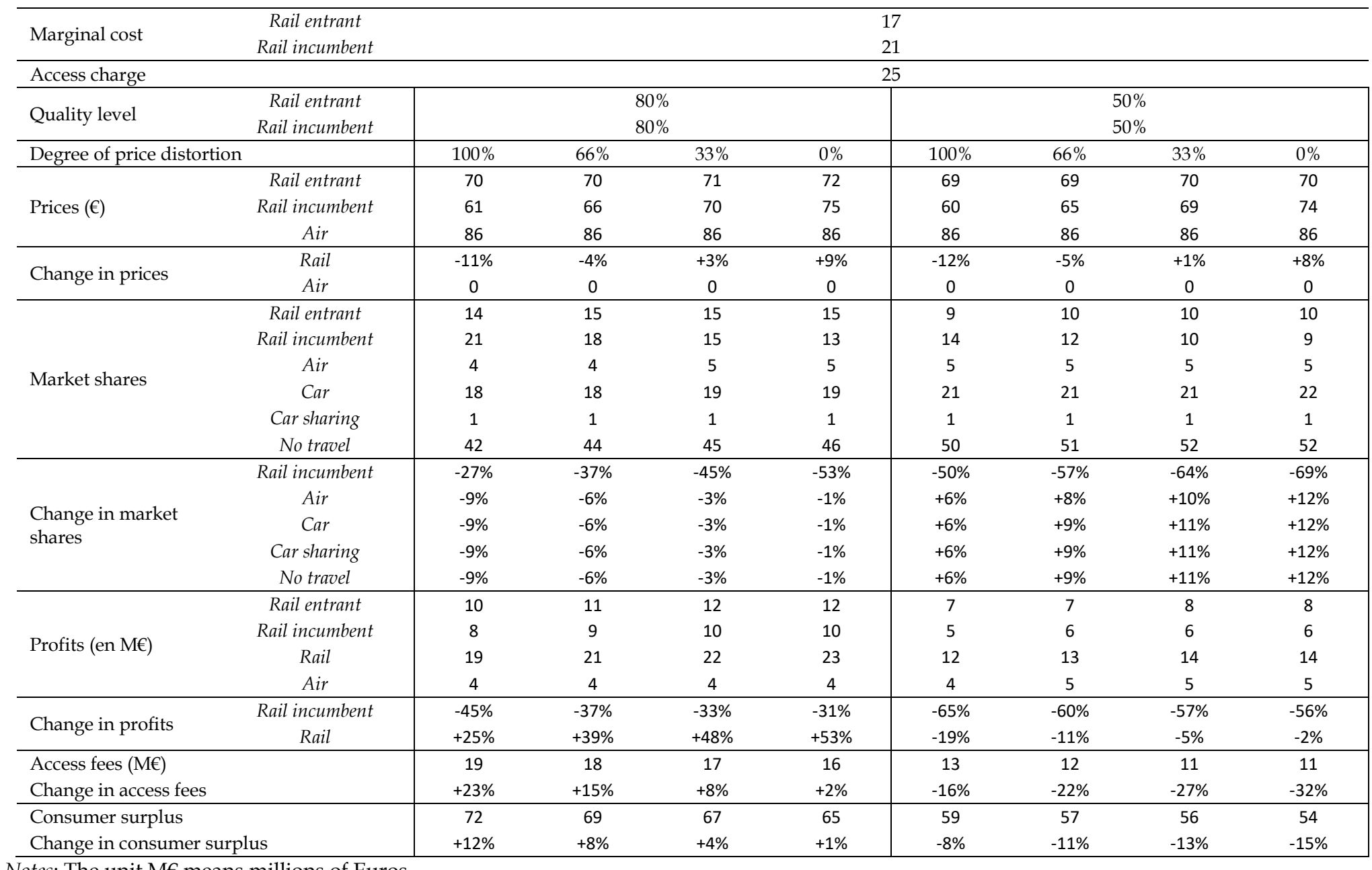

Notes: The unit M€ means millions of Euros. 
Table A3: Opening to competition for the market: Simulation results

\begin{tabular}{|c|c|c|c|c|c|c|c|c|c|c|c|c|c|}
\hline Marginal cost & Rail & \multicolumn{6}{|c|}{21} & \multicolumn{6}{|c|}{17} \\
\hline \multicolumn{2}{|l|}{ Access charge } & \multicolumn{12}{|c|}{25} \\
\hline Quality level & Rail & \multicolumn{12}{|c|}{$100 \%$} \\
\hline \multirow{2}{*}{ Prices $(€)$} & Rail & 61 & 64 & 66 & 73 & 79 & 85 & 57 & 60 & 62 & 69 & 75 & 81 \\
\hline & Air & 86 & 86 & 86 & 86 & 86 & 86 & 86 & 86 & 86 & 86 & 86 & 86 \\
\hline Change in prices & Rail & $-11 \%$ & $-6 \%$ & $-3 \%$ & $+7 \%$ & $+5 \%$ & $+24 \%$ & $-17 \%$ & $-12 \%$ & $-9 \%$ & $+1 \%$ & $+10 \%$ & $+18 \%$ \\
\hline \multirow{5}{*}{ Market shares } & Rail & 33 & 31 & 29 & 25 & 22 & 19 & 36 & 34 & 32 & 28 & 24 & 21 \\
\hline & Air & 4 & 5 & 5 & 5 & 5 & 5 & 4 & 4 & 4 & 5 & 5 & 5 \\
\hline & Car & 18 & 19 & 19 & 20 & 21 & 22 & 17 & 18 & 18 & 19 & 20 & 21 \\
\hline & Car sharing & 1 & 1 & 1 & 1 & 1 & 1 & 1 & 1 & 1 & 1 & 1 & 1 \\
\hline & No travel & 43 & 45 & 46 & 48 & 51 & 53 & 41 & 43 & 44 & 47 & 49 & 51 \\
\hline \multirow{2}{*}{$\begin{array}{l}\text { Change in market } \\
\text { shares }\end{array}$} & Car sharing & $-7 \%$ & $-4 \%$ & $-2 \%$ & $+4 \%$ & $+9 \%$ & $+13 \%$ & $-11 \%$ & $-8 \%$ & $-6 \%$ & $+1 \%$ & $+6 \%$ & $+10 \%$ \\
\hline & No travel & $-7 \%$ & $-4 \%$ & $-2 \%$ & $+4 \%$ & $+9 \%$ & $+13 \%$ & $-11 \%$ & $-8 \%$ & $-6 \%$ & $+1 \%$ & $+6 \%$ & $+10 \%$ \\
\hline \multirow{2}{*}{ Profits (en M€) } & Rail & 13 & 15 & 16 & 18 & 19 & 19 & 15 & 17 & 18 & 20 & 22 & 22 \\
\hline & Air & 4 & 4 & 4 & 4 & 5 & 5 & 4 & 4 & 4 & 4 & 4 & 5 \\
\hline \multirow{2}{*}{ Change in profits } & Rail & $-12 \%$ & 0 & $+7 \%$ & $+22 \%$ & $+29 \%$ & $+31 \%$ & 0 & $+14 \%$ & $+21 \%$ & $+38 \%$ & $+46 \%$ & $+48 \%$ \\
\hline & Air & $-7 \%$ & $-4 \%$ & $-2 \%$ & $+4 \%$ & $+9 \%$ & $+13 \%$ & $-11 \%$ & $-8 \%$ & $-6 \%$ & $+1 \%$ & $+6 \%$ & $+10 \%$ \\
\hline \multicolumn{2}{|l|}{ Access fees (M€) } & 18 & 17 & 16 & 14 & 12 & 10 & 20 & 19 & 18 & 15 & 13 & 12 \\
\hline \multicolumn{2}{|c|}{ Change in access fees } & $+18 \%$ & $+10 \%$ & $+5 \%$ & $-10 \%$ & $-23 \%$ & $-33 \%$ & $+28 \%$ & $+20 \%$ & $+15 \%$ & $-1 \%$ & $-15 \%$ & $-26 \%$ \\
\hline \multicolumn{2}{|c|}{ Consumer surplus } & 70 & 67 & 66 & 61 & 57 & 54 & 74 & 71 & 69 & 64 & 59 & 56 \\
\hline \multicolumn{2}{|c|}{ Change in consumer surplus } & $+9 \%$ & $+5 \%$ & $+2 \%$ & $-5 \%$ & $-11 \%$ & $-16 \%$ & $+15 \%$ & $+11 \%$ & $+8 \%$ & $-1 \%$ & $-7 \%$ & $-13 \%$ \\
\hline
\end{tabular}

Notes: The unit M€ means millions of Euros. 
Table A4: Comparison of types of opening up to competition (leisure segment - Paris-Marseille market)

\begin{tabular}{lcccccc}
\hline Type of competition & \multicolumn{3}{c}{ For the market } & \multicolumn{3}{c}{ In the market } \\
\hline Quality level of rail operators & $100 \%$ & $100 \%$ & $100 \%$ & $80 \%-50 \%$ & $80 \%-50 \%$ & $100 \%-10 \%$ \\
Degree of price distortion & $100 \%$ & $66 \%$ & $0 \%$ & $66 \%$ & $0 \%$ & $0 \%$ \\
\hline Change in consumer surplus & $+2 \%$ & $-5 \%$ & $-16 \%$ & $+0 \%$ & $-8 \%$ & $-14 \%$ \\
Change in profit & $+7 \%$ & $+22 \%$ & $+31 \%$ & $+14 \%$ & $+26 \%$ & $+32 \%$ \\
Change in access charges & $+5 \%$ & $-10 \%$ & $-33 \%$ & $-1 \%$ & $-15 \%$ & $-29 \%$ \\
\hline
\end{tabular}

Note: i) In case of opening for the market, the quality parameter is that of the franchised operator; in the case of opening in the market, the first value for the quality level is that of the historical operator and the second one, that of the new entrant. ii) In case of opening for the market, the tariff distortion is exerted on the franchised operator; in case of opening on the market, the tariff distortion is exerted only on the incumbent operator, the new entrant being supposed to maximize its profit of the short term. iii) In the case of competition for the market, the marginal cost of the operator is $10 \%$ lower than that of the incumbent. iv) In the case of competition in the market, the marginal cost of the incumbent is now $10 \%$ lower than it was in the status quo, and the marginal cost of the new entrant is $30 \%$ lower than that of the incumbent originally.

Table A5: Comparison of types of opening up to competition (business segment - Paris-Bordeaux market)

\begin{tabular}{lcccccc}
\hline Type of competition & \multicolumn{3}{c}{ For the market } & \multicolumn{3}{c}{ In the market } \\
\hline Quality level of rail operators & $100 \%$ & $100 \%$ & $100 \%$ & $80 \%-50 \%$ & $80 \%-50 \%$ & $100 \%-10 \%$ \\
Degree of price distortion & $100 \%$ & $66 \%$ & $0 \%$ & $66 \%$ & $0 \%$ & $0 \%$ \\
\hline Change in consumer surplus & $+2 \%$ & $-9 \%$ & $-25 \%$ & $-5 \%$ & $-15 \%$ & $-23 \%$ \\
Change in profit & $+4 \%$ & $+24 \%$ & $+36 \%$ & $+13 \%$ & $+28 \%$ & $+37 \%$ \\
Change in access charges & $+3 \%$ & $-13 \%$ & $-37 \%$ & $-7 \%$ & $-22 \%$ & $-34 \%$ \\
\hline
\end{tabular}




\section{Appendix 3: Figures}

Figure 1: Opening to competition in the market: Summary of main findings

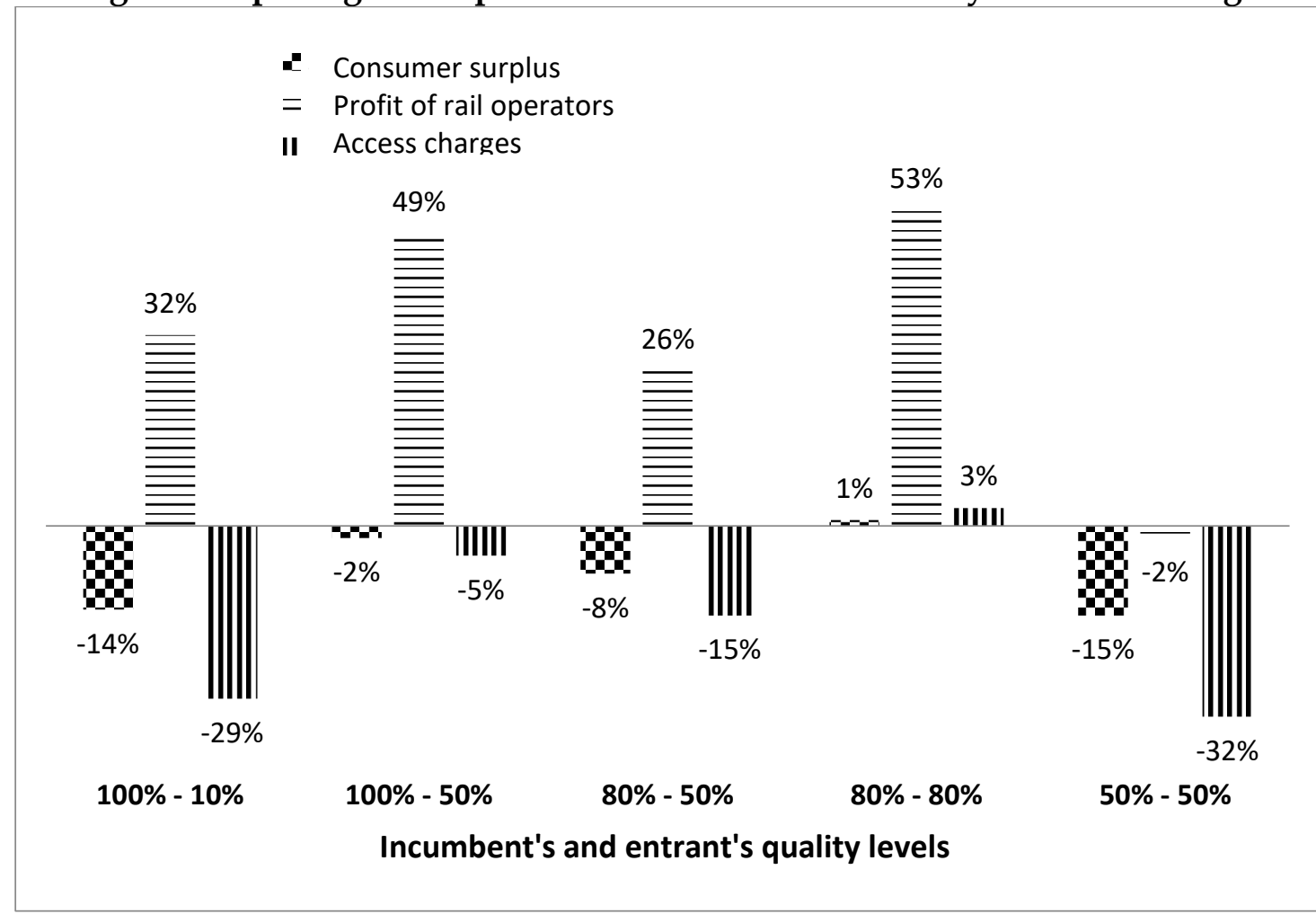

Figure 2: Opening to competition for the market: Summary of main findings
- Consumer surplus
$=$ Profit of rail operators
II Access charges

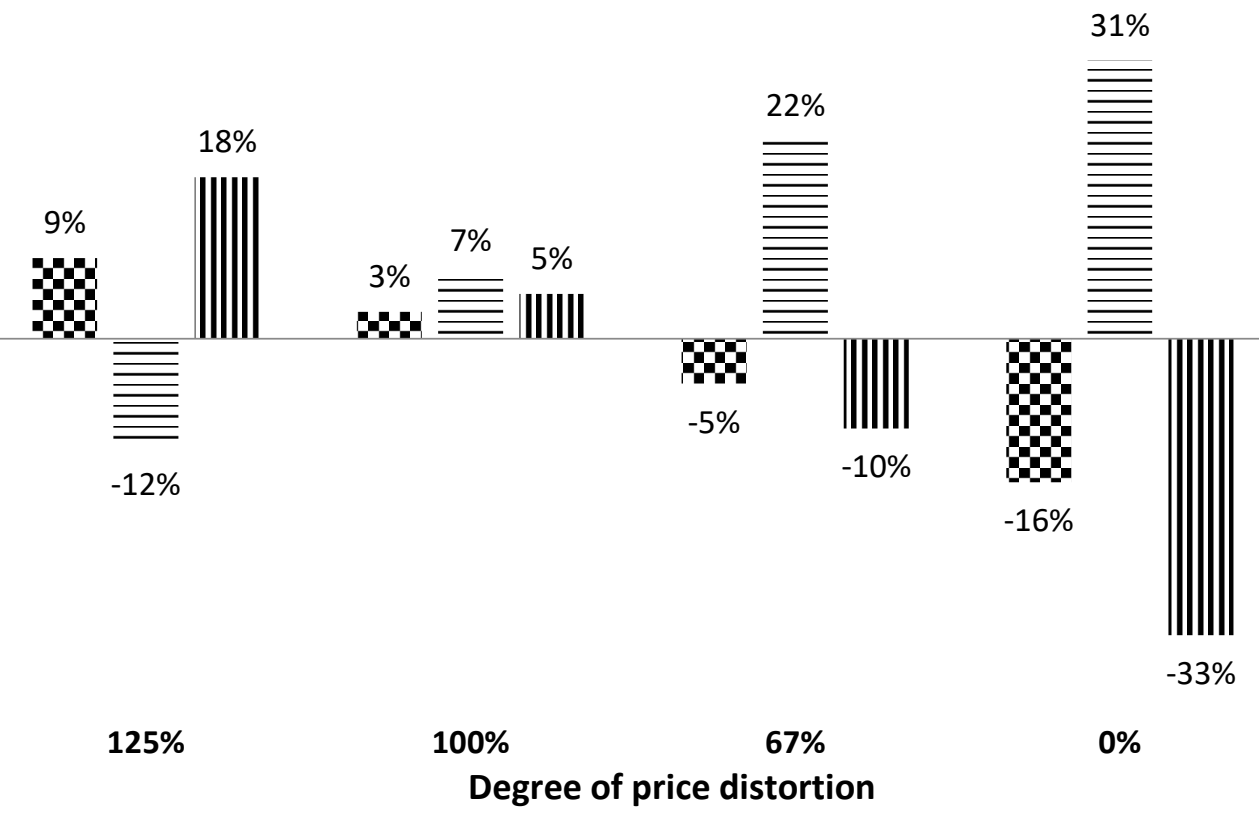




\section{References}

Álvarez-SanJaime, Ó., Cantos-Sanchez, P., Moner-Colonques, R. and J. J. Sempere-Monerris (2015), "A model of internal and external competition in a High Speed Rail line," Economics of Transportation, Vol. 4, No. 3, p. 178-187.

Bergantino, A.S. and C. Capozza (2015), "One price for all? Price discrimination and market captivity: evidence from the Italian city-pair markets," Transportation Research Part A: Policy and Practice, Vol. 75, p. 231-244.

Bergantino, A.S., C. Capozza and M. Capurso (2015), "The impact of open access on intra- and inter-modal rail competition. A national level analysis in Italy," Transport Policy, Vol. 39, p. 77-86.

Bureau of Transport and Regional Economics (2003), https:/ / bitre.gov.au/tedb/.

Campos, J., and G. De Rus (2009), "Some stylized facts about high-speed rail: A review of HSR experiences around the world," Transport policy, Vol. 16, No. 1, p. 19-28.

Competition \& Market Authority (2015)," Competition in passenger rail services in Great Britain," https://www.gov.uk/government/uploads/system/uploads/attachment_data/file/446 255/Passenger_rail_services_in_Great_Britain.pdf.

Competition \& Market Authority (2016), "Passenger rail services: competition policy project, " https://www.gov.uk/cma-cases/passenger-rail-services-competition-policy-project.

Enquête Nationale Transports et Déplacements (2008), Ministère de l'Écologie, de l'Énergie, du Développement durable et de la Mer, INSEE.

Fudenberg, D. and J. Tirole (2000), "Pricing a Network Good To Deter Entry," The Journal of Industrial Economics, Vol 48, 4, P. 373-390.

Ivaldi, M. and C. Vibes (2008), "Price competition in the intercity passenger transport market: a simulation model," Journal of Transport Economics and Policy, Vol. 42, No. 2, p. 225-254.

Johnson, D. and C. Nash (2012), "Competition and the provision of rail passenger services: A simulation exercise," Journal of Rail Transport Planning \& Management, Vol 2, No. 1, p. 14-22.

Link, H. (2004), "Rail infrastructure charging and on-track competition in Germany," International Journal of Transport Management, Vol. 2, No. 1, p. 17-27.

Milgrom, P., and J. Roberts (1982), "Limit pricing and entry under incomplete information: An equilibrium analysis," Econometrica, 443-459.

MVA Consultancy and The Institute for Transport Studies, (2011), Modelling the Impacts of Increased On-Rail Competition Through Open Access Operation, London: The Office of Rail Regulation.

Nash, C. (2018), "Rail Fiance in Europe," Review of Network Economics, forthcoming.

Nash, C., Crozet, Y., Nilsson, J.E. and H. Link (2016), Liberalisation of passenger rail services, CERRE Report.

Preston, J., Holvad, T. and F. Raje (2002), "Track Access Charges and Rail Competition: A Comparative Analysis of Britain and Sweden," European Transport Conference, Cambridge, September.

Preston, J., Whelan, G. and M. Wardman (1999), “An Analysis of the potential for on-track competition in the british passenger rail industry," Journal of Transport Economics and Policy, Vol. 33, No. 1, p. 77-94.

Rasmussen, T., Wheat, P., and A. Smith (2015), "Do open access train operators exhibit inherent cost benefits compared to their franchised counterparts," Econometric analysis of efficiency gains from on-rail competition, Hull Working paper.

Report of the Office of Rail and Road (ORR) (July 2015), "Impact Assessment of the CMA Options for Increasing On-Rail Competition."

Sappington, D. E., and J. G. Sidak (2003), "Incentives for anticompetitive behavior by public 
enterprises," Review of Industrial Organization, 22(3), p. 183-206.

Seabright, P., et al. (2003), “The economics of passenger rail transport: A survey,", IDEI Report.

Séguret, S. (2009), "Is competition on track a real alternative to competitive tendering in the railway industry? Evidence from Germany." International Conference Series on Competition and Ownership in Land Passenger Transport- Delft, The Netherlands - Thredbo 11

Smith, A., Nash C. and P. Wheat (2009), "Passenger rail franchising in Britain: has it been a success?," International Journal of Transport Economics/Rivista internazionale di economia dei trasporti, Vol.36, No. 1, p. 33-62.

Smith, A. S. and P. Wheat (2012), "Evaluating alternative policy responses to franchise failure: evidence from the passenger rail sector in Britain," Journal of Transport Economics and Policy (JTEP), Vol. 46, No. 1, p. 25-49.

Smith, A. S. and P. Wheat (2015), "Do the usual results of railway returns to scale and density hold in the case of heterogeneity in outputs? A hedonic cost function approach," Journal of Transport Economics and Policy (JTEP), Vol. 49, No. 1, p. 35-57.

Spinetta, J-C (2018), L'avenir du Transport ferroviaire, https://www.ecologiquesolidaire.gouv.fr/sites/default/files/2018.02.15_Rapport-Avenir-du-transportferroviaire.pdf.

Swan, W. M., and N. Adler (2006), "Aircraft trip cost parameters: A function of stage length and seat capacity," Transportation Research Part E: Logistics and Transportation Review, Vol. 42, No. 2, p. 105-115. 